\title{
THE AMERICAN MATHEMATICAL SOCIETY AND APPLIED MATHEMATICS
}

Since the beginning of World War II, there has been a growing emphasis on Applied Mathematics, a field in which American mathematicians had not been so active in the past decades. Many programs for Applied Mathematics were set up and mathematicians made great contributions to the solution of problems connected with the country's war effort. During the war the Society established a special Committee on Addresses in Applied Mathematics, under the chairmanship of Professor Richard Courant; this committee arranged symposia and invited addresses on topics of interest in Applied Mathematics. There was a widespread feeling that this activity should be continued and expanded.

At the time of the 1946 Summer Meeting at Cornell University, the Council of the Society discussed possible steps which might be taken toward the stimulation of the proper development in applied mathematics and the need for a program within the Society which would serve the needs of the applied mathematicians. As a result of this discussion, the President was authorized to appoint a committee to study these problems and the following Special Committee on Applied Mathematics was subsequently appointed: Professors J. L. Synge (Chairman), R. V. Churchill, Richard Courant, G. C. Evans, W. T. Martin, John von Neumann, and J. W. Tukey.

This Special Committee on Applied Mathematics presented recommendations to the Council at the 1946 Annual Meeting, providing for: (1) a study of financial support by the Society to the Journal of Mathematics and Physics and the Quarterly of Applied Mathematics by the appropriate committee of the Society; (2) the appointment of a Committee on Applied Mathematics which would organize programs in applied mathematics and make recommendations to the Council in all matters pertaining to the interests of applied mathematics; (3) the establishment of an annual symposium on applied mathematics, the proceedings of which might be published in book form. These recommendations were adopted by the Council.

The Special Committee on Applied Mathematics presented its final report to the Council in April, 1947, and at that time certain specific problems which this committee had had under discussion but on which it had come to no decision were referred to the Committee on Applied Mathematics. It further recommended to the Council that a statement entitled Instruction and Research in Applied Mathematics 
be published in the Bulletin. The Council approved this statement which is published in this issue of the Bulletin.

The Committee on Applied Mathematics has made plans for the first annual Symposium, on the topic of Non-linear problems in mechanics of continua, which will be held at Brown University on August 2-4, 1947.

The Committee on Applied Mathematics (Professors J. L. Synge, Chairman, Richard Courant, G. C. Evans, John von Neumann, William Prager, and Dr. Warren Weaver) invites suggestions from members of the Society regarding problems which should be studied by this committee and welcomes comments as to the manner in which the American Mathematical Society may aid in the development of Applied Mathematics in this country. Please communicate comments and suggestions to the Chairman of the Committee, Professor J. L. Synge, Carnegie Institute of Technology, Pittsburgh 13, Pennsylvania.

May 8, 1947.

J. R. KLINE, Secretary

\section{SECOND SYMPOSIUM ON APPLIED MATHEMATICS}

The American Mathematical Society will hold its second Symposium on Applied Mathematics in the summer of 1948, and seeks invitations from institutions willing to act as hosts.

The subject of the Symposium will be chosen by the Committee on Applied Mathematics in consultation with the host institution, and institutions offering themselves as hosts are requested to indicate the subject preferred. The subject might be defined in terms of recognized divisions of science or engineering, or it might be defined in terms of mathematical methods which cut across these divisions. The Committee will welcome suggestions for subjects not only from inviting institutions but also from members of the Society and others.

It is proposed that the Symposium will last two or three days, with four one-hour invited lectures at the Symposium, also a number of twenty-minute contributions (invited or uninvited), with adequate time for discussion.

Invitations from institutions willing to act as host should be sent, before September 30, 1947, to the Chairman of the Committee on Applied Mathematics, Professor J. L. Synge, Carnegie Institute of Technology, Pittsburgh 13, Pennsylvania. 